\title{
PERFÍS DOS PROFESIONAIS DA INFORMACIÓN E A SÚA RELACIÓN COA LINGUA
}

\section{Miguel Túñez López}

Facultade de Ciencias da Comunicación, USC

Os xornalistas galegos, na liña do que xa describira Warren Breed hai case medio século, seguen a aprender por osmose as regras non escritas do xornal, é dicir, son socializados nunha cultura lingüística que ninguén recoñece no seu discurso público e que os fai conformistas e escasamente críticos fronte ao sistema.

Todos os medios de comunicación establecen estratexias específicas para a súa propia actuación en relación cos sistemas económico, político e social. Co obxectivo preferente e permanente de lucrar e influír, a suma desas estratexias configura a política global do medio, entendendo como política a orientación evidenciada por un xornal non só no seu editorial senón tamén nas súas informacións e artigos, relativas a cuestións e acontecementos escolmados, de entre os que coñece, para seren difundidos.

Non todas estas actuacións que conforman o discurso e a imaxe pública do medio de comunicación son explícitas senón que algunhas se caracterizan pola súa reserva ou segredo. De feito, a estratexia informativa de cada medio é o conxunto de actuacións públicas e privadas, recoñecidas ou non, que explican o seu funcionamento como produtor de contidos informativos e como actor social e político. Só unha parte destas actuacións se manifesta no propio produto comunicativo e estas permítennos deducir cal é a estratexia global que as provoca; o resto son difíciles de comprobar pero pódense, cando menos, deducir.

No caso que nos ocupa, esa análise dedutiva é para intentar indagar no peso das estratexias lingüísticas na política do medio e a súa relación co cadro de persoal. As argumentacións recollidas neste relatorio son parte dunha investigación promovida polo Consello da Cultura Galega e o Colexio Profesional de Xornalistas de Galicia, e desenvolvida por un equipo da Facultade de Ciencias de Comunicación da USC ${ }^{1}$.

1. Integrado por Berta García Orosa, Marcos Pérez Pena, José Villanueva e Miguel Túñez López. 
Os traballos realizados en Galicia para determinar as condicións laborais dos informadores acostuman incorporar a lingua como un dos factores que ter en conta para describir a actividade laboral aínda que non afonden na relación que poida existir entre os dous vectores.

A comparativa dos perfís profesionais en función da lingua de referencia dos xornalistas na súa actividade profesional ou na súa vida persoal non ofrece datos que se poidan considerar estatisticamente significativos como identificadores dos galegofalantes ou dos castelanfalantes. Defínese maioritariamente o uso do galego como unha escolla que depende máis das normas da empresa que dunha aposta persoal dos periodistas, pero queda por desvelar claramente ata que punto hai unha correspondencia das actitudes lingüísticas dos medios coas preferencias de uso dos informadores e como inflúe na escolla da lingua como soporte informativo.

A relectura dos datos dos informes publicados en 2000 e 2002 permite tirar unhas primeiras conclusións que, polo menos, non deixan de ser curiosas. Por exemplo, no plano persoal, é dicir, no uso habitual da lingua, o perfil do galegofalante, do castelanfalante e dos que din ser bilingües é o mesmo: home, de 35 a 40 anos, que traballa na escrita e que ten estudos en Ciencias da Comunicación.

\begin{tabular}{|c|c|c|c|}
\hline Lingua habitual & Galegofalantes & Bilingües & Castelanfalantes \\
\hline SOPORTE & Prensa diaria $(39 \%)$ & Prensa diaria (57\%) & Prensa diaria $(20,8 \%)$ \\
\hline SeXo & Home $(70 \%)$ & Home $(55,6 \%)$ & Home (58\%) \\
\hline IDADE MEDIA & 36,6 & 38 & 37,8 \\
\hline NiVel de EStudos & $\begin{array}{c}\text { Lic. en CC. da } \\
\text { Comunicación }(50 \%) \\
\end{array}$ & $\begin{array}{c}\text { Lic. en CC. da } \\
\text { Comunicación }(50 \%)\end{array}$ & $\begin{array}{c}\text { Lic. en CC. da } \\
\text { Comunicación }(56,5 \%)\end{array}$ \\
\hline
\end{tabular}

Lingua preferente nas relacións persoais. Fonte: Túnez (2002)

Diferenciando pola escolla lingüística no ámbito laboral, os galegofalantes son os que din ter que traballar menos días ao mes e menos horas ao día e os castelanfalantes son os que aseguran percibir un maior salario mensual. 
Non pode falarse de diferenzas significativas, nin sequera de datos plenamente identificadores xa que a adscrición lingüística no ámbito laboral non foi un dos valores utilizados para a selección da mostra da enquisa, pero a modo unicamente ilustrativo podemos ver que unha nova explotación dos rexistros ${ }^{2}$ da enquisa a máis de 300 periodistas, publicado no 2002 polo Colexio de Xornalistas, a maioría dos que din falar galego no seu medio de traballo son homes de pouco máis de 30 anos que traballan na televisión pública, que elaboran preto de 4 informacións ao día, maioritariamente en galego e que están razoablemente satisfeitos co seu traballo xa que se sitúan nunha media de 6 puntos nunha escala do 1 ao 10.

Por outra parte, o perfil que describiría ao xornalista castelanfalante na redacción do medio en que traballa é o seguinte: home, de case 38 anos, que dedica máis de 8 horas e media de case 24 días do mes á súa actividade laboral; traballa nalgún medio impreso diario para o que elabora case 5 informacións cada xornada; percibe por esta actividade algo menos de 1200 euros mensuais e amosa unha satisfacción notable coa súa actividade profesional.

\begin{tabular}{|c|c|c|c|}
\hline $\begin{array}{c}\text { Uso da lingua no } \\
\text { ámbito laboral }\end{array}$ & Galegofalantes & Bilingües & Castelanfalantes \\
\hline SOPORTE & TV pública $(36,1 \%)$ & Prensa $(39,4 \%)$ & Prensa $(63,2 \%)$ \\
\hline SEXo & Home $(51 \%)$ & Home $(71,4 \%)$ & Home $(71 \%)$ \\
\hline IDADE & 34,8 & 41,5 & 37,7 \\
\hline TIPO DE XORNADA & Completa $(38,9 \%)$ & Completa $(57,1 \%)$ & Completa $(55,2 \%)$ \\
\hline DÍAS TRABALLADOS AO MES & 21,5 & 22,47 & 23,43 \\
\hline HORAS TRABALLADOS AO DÍA & 7,73 & 8,68 & 8,31 \\
\hline LINGUA EN QUE TRABALLAN & Galego $(48,8 \%)$ & Castelán $(74 \%)$ & Castelán $(50 \%)$ \\
\hline SATISFACCIÓN CO SALARIO $(1-10)$ & 6,15 & 5,62 & 5,43 \\
\hline SATISFACCIÓN CO TRABALLO $(1-10)$ & 6,26 & 6,17 & 6,91 \\
\hline INFORMACIÓNS ELABORA AO DÍA & 3,77 & 3,55 & 4,65 \\
\hline SALARIO MEDIO & $1096,7 €$ & $888,2 €$ & $1151,7 €$ \\
\hline
\end{tabular}

Lingua preferente nas relacións de traballo

2. Realizada no 2004 para unha investigación promovida polo Colexio de Xornalistas e o Consello da Cultura Galega. 
Cando se consideran as características lingüísticas en función do soporte en que traballan, os datos dos que se dispón ofrecen panoramas diferentes pero tamén debe terse en conta que se trata de estudos realizados sobre universos non coincidentes. No publicado en 2002, feito sobre os inscritos no CPXG, a lingua habitual dos xornalistas dista de ser uniforme e ofrece diferenzas significativas por soportes: o galego é maioritario para tres de cada catro xornalistas de gabinete, mentres que entre os xornalistas de axencia invértense as cifras e tres de cada catro empregan o castelán de forma habitual.

\begin{tabular}{|l|c|c|c|c|c|c|}
\hline $\begin{array}{c}\text { Lingua } \\
\text { habitual }\end{array}$ & Prensa & Radio & Televisión & Gabinete & Axencias & Outros \\
\hline CALQUERA & 15 & 33 & 36 & 5 & 47 & 37 \\
\hline CASTELÁN & 32 & 18 & 7 & 20 & 23 & 27 \\
\hline GALEGO & 53 & 48 & 56 & 75 & 30 & 36 \\
\hline
\end{tabular}

Lingua habitual, en función do medio. Fonte: Túñez (2002)

Segundo se tira do outro estudo significativo, feito sobre o censo de informadores galegos que tiven a sorte de coordinar por encargo do Consello da Cultura Galega, os galegofalantes son unha maioría moi clara (seis de cada dez) en televisión e gabinetes e mais na docencia (a práctica totalidade), mentres que os castelanfalantes son máis na prensa, radio e axencias (nestes dous últimos soportes, de xeito claro).

\begin{tabular}{|c|c|c|c|}
\hline Soporte & Galego & Castelán & Bilingüe \\
\hline PRENSA & 38,5 & 55,4 & 6,1 \\
\hline RADIO & 24,1 & 63 & 12,9 \\
\hline TV & 57,4 & 37,7 & 4,9 \\
\hline GABINETE & 65,5 & 27,6 & 6,9 \\
\hline AXENCIA & 31,6 & 68,4 & 0 \\
\hline DOCENCIA & 85,7 & 14,3 & 0 \\
\hline
\end{tabular}

Lingua habitual, en función do medio. Fonte: Túñez/López (2000) 
Estas diferenzas tamén poden vir dadas polo mecanismo de recolla de datos que nun estudo (2000) baséase na lingua pola que se decanta o entrevistado e no outro (2002) nas afirmacións de uso lingüístico que declara, pero que revelan que o galego se usa menos do que realmente se di que se emprega.

\begin{tabular}{|c|c|c|}
\hline Lingua & Usada & Declarada \\
\hline CASTELÁN & 50,3 & 23,9 \\
\hline GALEGO & 43 & 53,2 \\
\hline AS DÚAS & 6,7 & 22,9 \\
\hline FONTE & Túñez/López, 2000 & Túñez, 2002 \\
\hline
\end{tabular}

Lingua usada e declarada

Principalmente desde unha perspectiva exploratoria e para unha análise cualitativa, optouse por complementar os datos que ofrecía a reinterpretación dos estudos existentes con entrevistas individuais aos responsables dos medios impresos (maioritarios en cantidade de traballadores e tamén nos tres perfís) e por entrevistas colectivas (grupos de discusión) a xornalistas, por un lado, e a especialistas de áreas afíns ${ }^{3}$, polo outro.

Todas as investigacións realizadas sobre a presenza do galego nos medios de comunicación de Galicia coinciden en destacar un uso da lingua propia limitado ás radios e televisións de titularidade pública. No resto, sobre todo na prensa, dáse un estancamento de cifras case simbólicas: só de 3 a 4 de cada 100 páxinas de información van en galego.

Debuxando con brocha gorda, o escenario informativo podería esbozarse referenciado nun dominio do galego na televisión (polo peso da TVG e TVE no conxunto das redaccións galegas), o bilingüismo na radio (o galego da RG e, nas emisións para Galicia, de $\mathrm{RNE}^{4}$ quedan contrarrestadas pola variedade de escolla

3. Un dos grupos de discusión reuniu a expertos en psicoloxía, socioloxía, literatura, historia, lingua, medicina e márketing para falar do galego como vehículo das informacións relacionadas cos seus ámbitos.

4. As emisións para Galicia fanse integramente en galego desde outubro de 2004. 
lingüística de todas as canles privadas) e o predominio do castelán na prensa en papel e en internet.

\section{A LINGUA DA PRENSA}

Centrándonos nos medios escritos, a primeira característica dos fluxos da produción xornalística que provocan esa presenza testemuñal do emprego do galego é a ausencia dunha normativización do uso dentro do xornal. En ningún caso existen pautas fixas sobre cando e como se emprega o galego nas informacións. Unicamente nalgún caso excepcional os directores dos medios consultados recoñecen a existencia de consignas internas que circulan e se manteñen na redacción de xeito informal e aleatorio. Soamente unha cuarta parte dos xornais editados en Galicia manifesta recoller formalmente algunha regulación neste sentido e, en todos eles, caracterizada pola súa parcialidade xa que, cando existen, esas normas están reducidas a aspectos morfolóxicos ou sintácticos da redacción dos textos informativos.

Non obstante, esta carencia ten que ser interpretada nun contexto de falla de regulación ou actualización das normas da actividade xornalística que poderiamos sintetizar nos seguintes indicadores:

a) Ausencia de libros de estilo que unifiquen o traballo do xornal. Soamente a metade dos directores asegura que contan con libro de estilo ou con regulamentos similares.

b) A comunicación interna formal e regulada dentro dos xornais é practicamente inexistente. Este fluxo comunicativo englobaría ao conxunto de actividades efectuadas por calquera organización para a creación de mantemento de boas relacións con e entre os seus membros a través do emprego de diferentes formas e canles de comunicación, que os manteña informados, integrados e motivados, para contribuír co seu traballo ao logro dos obxectivos da organización. A comunicación informal sería aquela que se 
caracteriza pola súa espontaneidade e falla de formalización. É máis vaga que a formal, maniféstase continuamente de moitos xeitos e aparece como un fluxo incontrolado de información fronte á comunicación formal, que é o conxunto de procesos comunicativos que se establecen dentro da organización de xeito estruturado, programado e consciente -o obxectivo, non o resultado-.

c) Entre as xustificacións desta situación achegadas polos entrevistados -case un 40\%-, destaca que a ausencia de regulamentación está potenciada pola deficiente normativización do galego na actualidade -no momento de realización das conversas reclamaban a publicación da nova normativa do galego-.

d) Persiste a crenza de que o galego non é un soporte lingüístico rendible. Hai unha carencia de regulación interna do galego que en parte podería vir provocada polo posible condicionamento da regulación externa a través de incentivos de diverso tipo. Os únicos incentivos que se levan a cabo na actualidade son os económicos externos, dos que se admite que condicionan aínda que non consoliden o emprego do galego na lingua de publicación do xornal. Curiosamente máis da metade dos directores consultados estarían de acordo coa subvención dun xornal escrito en galego pero a porcentaxe dos que consideran que este financiamento público sería a única forma de que o produto subsistise sobe ata o $90 \%$.

e) As empresas xornalísticas galegas non recoñecen a existencia de sancións explícitas ou incentivos internos ao medio de comunicación relativos ao emprego dunha ou outra lingua. Non obstante, as conversas cos xornalistas descobren a existencia en determinados casos de incentivos informais á hora de cubrir determinados temas se se escribe no idioma maioritario. Puntualmente tamén se desvelaban situacións de discriminación polo descoñece- 
mento por parte do directivo do emprego normativo do galego escrito.

f) Soamente nunha pequena parte dos xornais analizados aparecen categorías laborais especificamente relacionadas coa lingua galega, mentres que na práctica totalidade dos xornais existen empregados correctores de textos en castelán. Do mesmo xeito, non rexistramos ningunha política laboral especificamente relacionada co idioma nin como incentivos nin como formación dos traballadores e dos empregados.

g) Case na totalidade dos rotativos consultados as relacións laborais formais establécense en castelán. Segundo os datos recollidos a través das entrevistas cos directores, grupos de discusión e enquisas a medios, o emprego da lingua non aparece nunca formalmente regulado pero o emprego do castelán é case o único utilizado para a realización de convenios, contratos e outros instrumentos da comunicación interna.

h) No caso da comunicación externa -con outros públicos- a lingua empregada maioritariamente continúa sendo o castelán, aínda que as empresas se adaptan neste caso ao idioma empregado polo seu interlocutor.

A modo de resumo pode apuntarse que non existe unha política explícita sobre o emprego da lingua pero todos os xornalistas coñecen cales son as normas informais ou non escritas que rexen en cada redacción. Pese a que a maioría do xornal aparece publicado en castelán e nalgunha ocasión son os propios xornalistas os que deciden o idioma empregado, os traballadores sinalan que non coñecen os criterios ou normas escritas que indiquen cales son os parámetros que se deben seguir. Segundo manifestou a maioría dos participantes nos grupos de discusión, a única regra non escrita no caso dos xornais é que o castelán sempre ten que predominar nunha porcentaxe alta e que aqueles temas de maior importancia ou cobertura aparecerán prioritariamente escritos en castelán. 
Os xornalistas galegos, na liña do que xa describira Warren Breed ${ }^{5}$ hai case medio século, seguen a aprender por osmose as regras non escritas do xornal, é dicir, son socializados nunha cultura lingüística que ninguén recoñece no seu discurso público e que os fai conformistas e escasamente críticos fronte ao sistema. A situación chega ata o punto de que os xornalistas manifestan nun primeiro momento que non existe ningunha norma ou indicación formal no medio de comunicación que obrigue a empregar unha lingua ou outra segundo as circunstancias, senón que é unha decisión do propio xornalista. Pero a continuación todos os traballadores de medios impresos que participaron nos grupos de discusión sinalaron o uso do galego como algo circunstancial, que en ningún momento pode superar a cota de textos en castelán que inclúe o xornal:

- Se eu escribía en galego o resto escribía en castelán, para manter o equilibrio.

- Tiña que pesar máis o castelán no global do xornal.

A medida que se afonda no tema son significativas as achegas puntuais dalgúns xornalistas porque serven para ilustrar perfectamente como se desenvolve esa transmisión das normas que non existen pero todos coñecen: por incidentes. Breed nega a esixencia de sancións para a aprendizaxe ou socialización e sinala como esta ás veces funciona a través de incidentes sobre o tema que o propio traballador recorda, interioriza e aplica en seguintes ocasións. Neste sentido, os xornalistas galegos fan referencia a algún caso concreto en que os xefes do medio de comunicación limitaron o uso do galego e isto permitiulles albiscar a política lingüística que se agochaba debaixo:

5. Breed, Warren (1955), «Social Control in the Newsroom: A Functional Analysis», en Social Forces, vol. 33. 
A primeira vez que me limitaron algo foi cando tiven que facer de correspondente de Sanxenxo porque o criterio foi o das vendas porque como en Sanxenxo no verán hai máis madrileños que galegos tiña que ir en castelán, sobre todo se abría a sección ou se o tema era a praia.

En principio podes escribir todo o que queiras pero se te pasas, danche o toque.

A maioría das achegas dos xornalistas e dos expertos que participaron nos grupos de discusión da referida investigación promovida polo Colexio Profesional de Xornalistas de Galicia e a Sección de Comunicación do Consello da Cultura Galega coinciden en sinalar que descoñecen as razóns ou criterios empregados polos medios de comunicación para optar polo emprego dun idioma ou outro. Con todo, podemos observar catro tendencias.

1. A primeira delas é a crenza de que a prensa en galego non vende. Os datos estatísticos de proporción de galego na publicidade duplican os da información, aínda que as institucións públicas amparan o 50\% dos anuncios e a empresa privada o $20 \%$.

2. A segunda razón é a idea de que o público obxectivo dos xornais de información xeral e diaria en Galicia rexeitaría o emprego maioritario ou único do galego.

3. En terceiro lugar, os participantes sinalan o feito de que moitos redactores teñen dificultades para escribir en galego.

4. A cuarta razón sería a propia cultura mediática ou o costume (en suma, a rutina) como un dos factores importantes para que se manteña unha alta porcentaxe de información en castelán.

Esta cultura mediática en castelán refórzase porque esta é tamén a lingua maioritariamente empregada como vehículo de comunicación interna entre os propios redactores e entre os xornalistas e os cadros de mando. O galego non é soporte único nin 
sequera nas relacións laborais que se dan nos medios que o teñen como única lingua de contacto coa audiencia ${ }^{6}$.

Mesmo se chega a admitir que se ben non existe discriminación á hora de contratar un traballador que fale habitualmente en galego, este tería máis obstáculos na súa profesión se só fala galego que se só fala castelán. Nesa liña apuntan testemuñas de casos persoais nos que a actitude da empresa pasaba por esixir que se disimulara o acento galego para locutar en castelán.

...me dicían iso, que non podía ser que este acento, que o tiña que quitar, incluso cando era información para Galicia.

Na comunicación externa, para rematar, o idioma empregado polas empresas informativas galegas adáptase aos seus públicos. No conxunto de mensaxes emitidas pola organización cara aos seus diferentes públicos externos, encamiñados a manter ou mellorar as súas relacións con eles, a proxectar unha imaxe favorable ou a promover as súas actividades, produtos e servizos, a empresa emprega a lingua do receptor cando este é un cliente ou condiciona a escolla lingüística se esa relación é cunha fonte.

A influencia da lingua nas relacións dos xornalistas coas fontes informativas delimitábase a dous casos principais aparentemente contraditorios pero que son, en realidade, complementarios:

a) a facilidade para influír na lingua empregada polas fontes de información en función do idioma empregado polo xornalista que, como orixe da conversa, podería marcar a dinámica desta;

6. Todos os participantes coinciden en afirmar que, independentemente do soporte e da empresa xornalística, a maior parte dos periodistas da redacción falan fundamentalmente castelán. Os casos de galegofalantes son tan puntuais que todos os membros do grupo son capaces de recordar todas as persoas e incluso o lugar na redacción dos traballadores que falaban galego; por exemplo: «Maioritariamente falábase castelán, agás o de deportes, que falaba galego»; "Os únicos que falaban en galego era o de deportes e os de comarcas». 
b) a existencia -aínda- dun prexuízo contra o galego e unha valoración moi alta dos medios de comunicación, o que cohibiría os posibles declarantes para empregar o galego. As fontes falan en castelán non porque se expresen mellor en castelán senón porque teñen asimilado que o discurso social ou público vai ser en castelán:

As fontes dan por suposto que falar para os medios é un acto de nivel e falan en castelán. 


\section{REFERENCIAS BIBLIOGRÁFICAS}

TúNEE, M. (2002), A situación laboral dos xornalistas galegos. Santiago de Compostela. Colexio Profesional de Xornalistas de Galicia.

López, X. e TúÑEz, M. (2000), Condicións laborais e actitudes profesionais nos medios de comunicación. Santiago de Compostela. Consello da Cultura Galega.

BreEd, W. (1955), «Social Control in the Newsroom: A Functional Analysis», en Social Forces, vol. 33. 